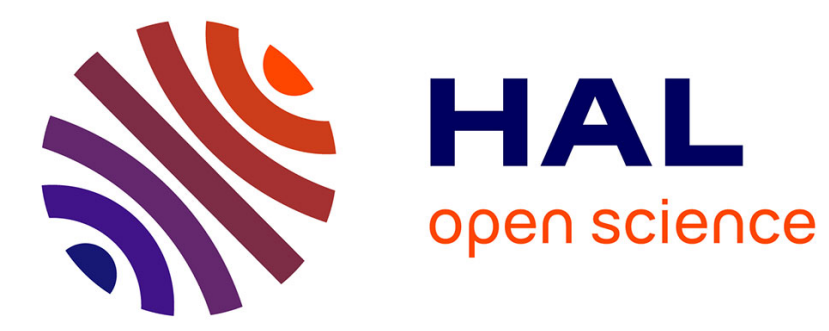

\title{
Effects of size and geometry on the plasticity of high strength copper/tantalum nanofilamentary conductors obtained by severe plastic deformation
}

Vanessa Vidal, Ludovic Thilly, Florence Lecouturier, Pierre-Olivier Renault

\section{- To cite this version:}

Vanessa Vidal, Ludovic Thilly, Florence Lecouturier, Pierre-Olivier Renault. Effects of size and geometry on the plasticity of high strength copper/tantalum nanofilamentary conductors obtained by severe plastic deformation. Acta Materialia, 2006, 54 (4), pp.1063-1075. 10.1016/j.actamat.2005.10.031 . hal-00118779

\author{
HAL Id: hal-00118779 \\ https://hal.science/hal-00118779
}

Submitted on 13 Aug 2020

HAL is a multi-disciplinary open access archive for the deposit and dissemination of scientific research documents, whether they are published or not. The documents may come from teaching and research institutions in France or abroad, or from public or private research centers.
L'archive ouverte pluridisciplinaire HAL, est destinée au dépôt et à la diffusion de documents scientifiques de niveau recherche, publiés ou non, émanant des établissements d'enseignement et de recherche français ou étrangers, des laboratoires publics ou privés. 


\title{
Effects of size and geometry on the plasticity of high-strength copper/tantalum nanofilamentary conductors obtained by severe plastic deformation
}

\author{
V. Vidal ${ }^{\mathrm{a}, \mathrm{b}}$, L. Thilly ${ }^{\mathrm{b}, *}$, F. Lecouturier ${ }^{\mathrm{a}}$, P.-O. Renault ${ }^{\mathrm{b}}$ \\ a Laboratoire National des Champs Magnétiques Pulsés, CNRS - Université Paul Sabatier Toulouse III - INSA, 143 Avenue de Rangueil, \\ 31432 Toulouse, France \\ b Laboratoire de Métallurgie Physique, Université de Poitiers, SP2MI, Teleport 2, BP 30179, Bd M. et P. Curie, 86960 Futuroscope, France
}

\begin{abstract}
Copper-based high-strength nanofilamentary wires reinforced by tantalum nanofilaments were prepared by severe plastic deformation (repeated hot extrusion and cold drawing steps) to be used in the windings of high-pulsed magnets. This application requires a complete characterization of the microstructure and the strength and their relationship for further optimization: after heavy strain, the $\mathrm{Cu}$ matrix is nanostructured and the Ta nanofilaments develop a strong ribbon-like shape resulting in an early microstructural refinement. The macroscopic strength is greater than rule-of-mixture predictions as confirmed by nanohardness values. The observed size effect is related to the dislocation starvation in the nanostructured materials combined with the barrier role of $\mathrm{Cu} / \mathrm{Ta}$ interfaces. The strengthening is lower, however, as expected, because of the distorted ribbon morphology of the Ta filaments preventing them from behaving as nanowhiskers, as $\mathrm{Nb}$ fibers do in $\mathrm{Cu} / \mathrm{Nb}$ wires. This shows that size and geometry play key roles in the plasticity of nanomaterials.
\end{abstract}

Keywords: Severe plastic deformation; Nanoindentation; TEM; Nanostructure; Fiber-reinforced composites

\section{Introduction}

The design and construction of non-destructive highfield magnets still represent a significant challenge for materials selection and development because the components have both structural (high elastic limit) and functional (high electrical conductivity) requirements that are usually contradictory. As an example, the production of fields above $80 \mathrm{~T}$ requires conducting materials possessing an electrical resistivity close to that of annealed copper $(0.2 \mu \Omega \mathrm{cm}$ at $77 \mathrm{~K})$ and a yield stress as high as possible (above $1.8 \mathrm{GPa}$ at $77 \mathrm{~K}$ ) to support the Lorentz forces without damage [1]. Up to now, reinforced copper-based wires have shown the best compromise between these two

\footnotetext{
* Corresponding author. Tel.:+335494968 31; fax: +33549496692. E-mail address: ludovic.thilly@univ-poitiers.fr (L. Thilly).
}

criteria; in particular, the copper/niobium $(\mathrm{Cu} / \mathrm{Nb})$ system has been studied for decades since it has very good mechanical properties that are much better than rule-of-mixture ( $\mathrm{ROM}$ ) predictions when the size of the $\mathrm{Nb}$ filaments is reduced to the sub-micrometer range. It should be emphasized that two main fabrication routes have been studied: production of nanofilamentary $\mathrm{Cu} / \mathrm{Nb}$ wires via severe plastic deformation (SPD) of: (i) arc-melted $\mathrm{Cu}-\mathrm{Nb}$ ingots, initially consisting of a $\mathrm{Cu}$ matrix containing $\mathrm{Nb}$ dendrites, so-called "in situ" composites; and (ii) bulk $\mathrm{Cu}$ tubes and $\mathrm{Nb}$ rods, giving rise to a $\mathrm{Cu}$ matrix containing $\mathrm{Nb}$ continuous filaments, so-called "continuous" composites [2-13].

The Laboratoire National des Champs Magnétiques Pulsés (Toulouse, France) has been involved in the improvement of these continuous composite materials for more than a decade: a fabrication process based on SPD through repeated extrusion, cold drawing and 
restacking steps has been developed. The best first generation of $\mathrm{Cu} / \mathrm{Nb}$ "continuous" nanocomposite conductors were composed of a copper matrix containing $N=55^{4}=9.15 \times 10^{6}$ parallel continuous $\mathrm{Nb}$ filaments with a diameter of $40 \mathrm{~nm}$. At $77 \mathrm{~K}$, they possess an ultimate tensile strength (UTS) of $2 \mathrm{GPa}$ and a resistivity of $0.6 \mu \Omega \mathrm{cm}$ for a $0.04 \mathrm{~mm}^{2}$ section [14]. However, conductors with a section between 3 and $7 \mathrm{~mm}^{2}$ are required for use in pulsed magnets. Therefore, the effect of SPD on the microstructure as well as the influence of nanometer size on the plasticity of nanofilamentary $\mathrm{Cu} / \mathrm{Nb}$ wires have been studied by in situ deformation using transmission electron microscopy (TEM), tomographic atomic probes, classic tensile tests and nanoindentation tests. The result is the definition of parameters for mechanical optimization (see Ref. [15] for a complete summary of these studies). Thus, a second generation of $\mathrm{Cu} / \mathrm{Nb}$ wires containing $N=85^{4}=52.2 \times 10^{6}$ parallel continuous $\mathrm{Nb}$ filaments were fabricated: the best nanofilamentary "continuous" conductor, containing $\mathrm{Nb}$ filaments with diameters of $142 \mathrm{~nm}$, shows for a section of $5 \mathrm{~mm}^{2}$ an UTS of $1.9 \mathrm{GPa}$ and a resistivity of $0.58 \mu \Omega \mathrm{cm}$ at $77 \mathrm{~K}$ [16].

Studies of strengthening mechanisms have led to different ways of optimization. One is based on the following result: the strength of $\mathrm{Nb}$ nanofibers was observed to be inversely proportional to their diameter and approached, for the smallest diameters, the theoretical strength for perfect crystals, $\mu / 2 \pi$, where $\mu$ is the shear modulus; the $\mathrm{Nb}$ filaments can therefore be considered as nanowhiskers $[13,17]$. Since the shear modulus of tantalum $(\mathrm{Ta})$ is higher than that of $\mathrm{Nb}\left(\mu_{\mathrm{Ta}}=69 \mathrm{GPa}>\mu_{\mathrm{Nb}}=40 \mathrm{GPa}\right)$, the $\mathrm{Cu} / \mathrm{Ta}$ system is assumed to induce better mechanical properties. The same trend is expected using $\mathrm{Fe}$ as the reinforcing phase, since $\mu_{\mathrm{Fe}}=80 \mathrm{GPa}$ (in this case, however, poorer electrical properties are expected due to the miscibility between $\mathrm{Cu}$ and $\mathrm{Fe}$ at high temperatures). In the literature, numerous studies of heavily deformed composites which consist of a face-centered cubic (fcc) matrix and a body-centered cubic (bcc) reinforcing phase are reported: "in situ" $\mathrm{Cu} / \mathrm{Nb}[2-12], \mathrm{Cu} / \mathrm{Ta}[18,19]$ and $\mathrm{Cu} / \mathrm{Fe}[20,21]$ systems. They all illustrate the considerable interest in $\mathrm{Cu}$-based $\mathrm{fcc} / \mathrm{bcc}$ composites because of the good combination of conductivity and strength. In particular, the improved strength observed in "in situ" $\mathrm{Cu} / \mathrm{Ta}$ nanocomposites compared to "in situ" $\mathrm{Cu} / \mathrm{Nb}$ ones $[18,19]$ seems to confirm that $\mathrm{Cu} / \mathrm{Ta}$ wires exhibit better strengthening mechanisms. The crucial point is to understand the origin of such increased strength: does it derive from intrinsic properties of the Ta component (in the bulk state, $\mathrm{Ta}$ is harder than $\mathrm{Nb}$ ) or from microstructural features such as geometry of the reinforcement or size effect on the composite plasticity (whisker effect in the Ta fibers or other dimensional dependence)?

In order to attempt to answer this question, we report here some recent developments of "continuous" $\mathrm{Cu} / \mathrm{Ta}$ ultrahigh-strength conductors, and compare their properties to "continuous" $\mathrm{Cu} / \mathrm{Nb}$ nanofilamentary wires.
Therefore, this paper reports on the complete characterization of different $\mathrm{Cu} / \mathrm{Ta}$ samples taken throughout the fabrication process. The electrical resistivity was measured using the four-probe technique, while the microstructure was characterized using scanning electron microscopy (SEM), TEM and X-ray diffraction (XRD); the mechanical properties were investigated using macroscopic tensile tests, as well as nanoindentation. Particular care was taken to link the characterization results obtained at different length scales (micro-/macroscale).

\section{Fabrication process of $\mathrm{Cu} / \mathrm{Ta}$ nanofilamentary wires by SPD}

As mentioned earlier, the $\mathrm{Cu} / \mathrm{Ta}$ system was chosen for the higher value of shear modulus of Ta with respect to $\mathrm{Nb}$. Its co-deformation behavior was initially investigated by cold drawing: radial and longitudinal oscillations were observed at the $\mathrm{Cu} / \mathrm{Ta}$ interface leading to untimely fracture [22]. To prevent this phenomenon, a hot extrusion stage was added prior to the cold drawing process. The stress field is indeed simplified during extrusion since only section reduction occurs in the die; moreover, the hightemperature deformation induces a faster development of instabilities: after hot extrusion, only the radial undulations (i.e. the non-prejudicial ones) are developed and they attain an equilibrium state. During the subsequent cold drawing process, the $\mathrm{Cu} / \mathrm{Ta}$ interfaces do not evolve further and early fractures are stopped.

Sophisticated "continuous" nanofilamentary $\mathrm{Cu} / \mathrm{Ta}$ conductors were therefore fabricated via SPD applied by hot extrusion and cold drawing, together with bundling stages in order to reduce the fiber size. In the first stage a Ta rod was inserted in an oxygen-free high-conductivity (OFHC) $\mathrm{Cu}$ tube. The billet was processed by hot extrusion and cold drawn to a hexagonal shape. To reduce the filament size, the hexagonal composite wire was cut into 85 segments to be bundled into a can of OFHC $\mathrm{Cu}$ and reduced as in the first stage. The series of hot extrusion/ cold drawing/bundling was repeated $n$ times $(n \leqslant 4)$ to obtain conductors containing $N=85^{n}$ Ta nanofibers, resulting from a first optimization of engineering parameters [23]. $\mathrm{Cu} / \mathrm{Ta}$ nanocomposites containing up to $N=85^{4}$ Ta nanofibers were successfully fabricated. Theoretically, the filaments have a known distribution and bundles are separated by channels of pure $\mathrm{Cu}$.

To illustrate the structure, a conductor, containing $85^{3}$ Ta fibers and cold drawn down to a hexagonal shape $(h=3.35 \mathrm{~mm})$ with one intermediate annealing, is presented in Fig. 1. Groups of $85 \mathrm{Ta}$ fibers are observed, whereas the $\mathrm{Cu}$ matrix is distributed into the interfilamentary channels $(\mathrm{Cu}-0)$, the superfilamentary channels $(\mathrm{Cu}-1)$, etc.

Table 1 gives the theoretical dimensional properties of the $\mathrm{Cu} / \mathrm{Ta}$ composites at different fabrication stages. The scale of the structure before and after drawing can be described using a similitude model, where the reduction 


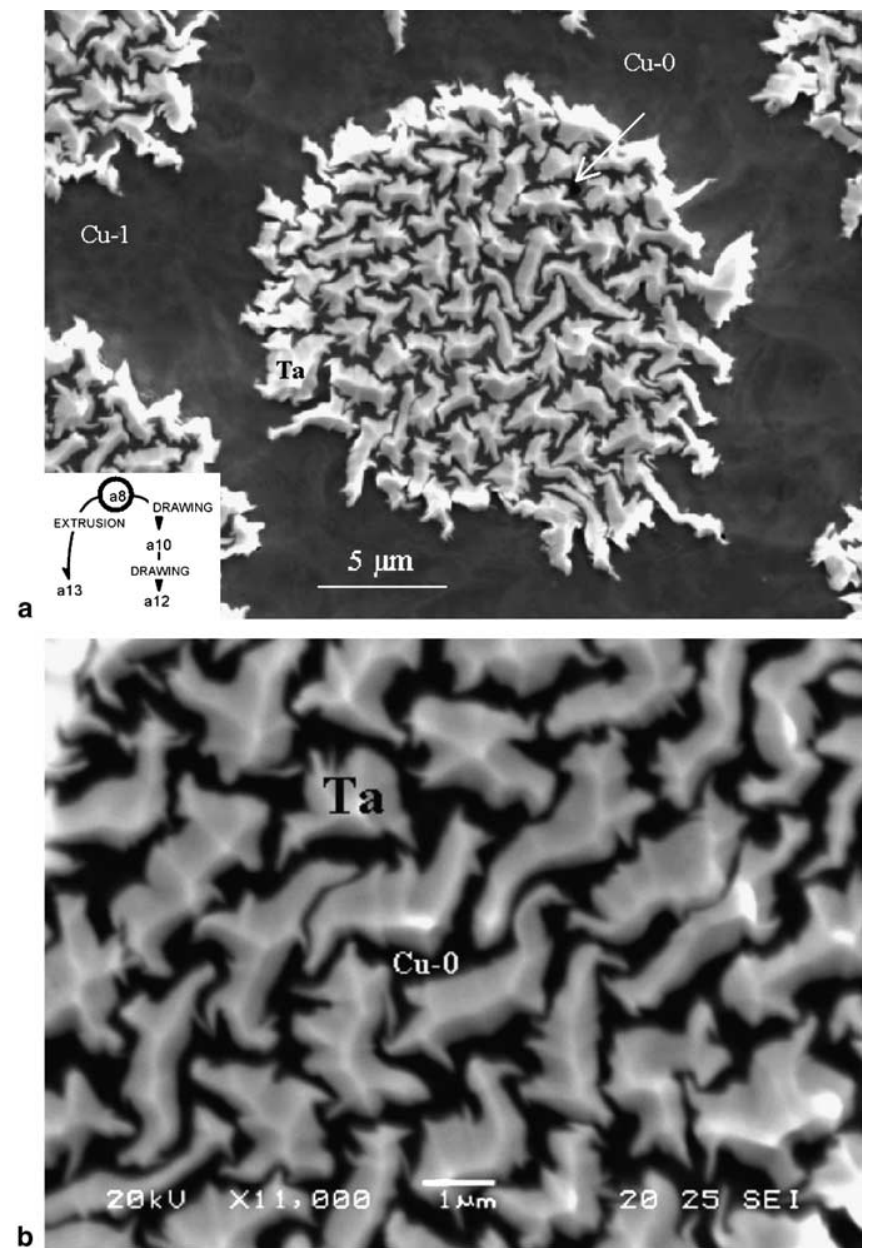

Fig. 1. (a) High-magnification cross-section SEM image of a $\mathrm{Cu} / \mathrm{Ta}$ wire (sample a8: $N=85^{3}, h=3.35 \mathrm{~mm}$ ). (b) Close-up view of the $\mathrm{Ta}+\mathrm{Cu}-0$ region.

of the scale of the structure is proportional to the strain. The total logarithmic true strain or drawing ratio $(\eta)$ is given by $\eta=\ln \left(A_{0} / A\right)$, where $A$ is the section of the wire and $A_{0}$ is the initial section of the billet. The reduction in area (RA) is also defined as $\mathrm{RA}=\left(A_{i}-A\right) / A_{i}$, where $A_{i}$ is the section of the wire at the previous recrystallization annealing stage. It is worth mentioning that after each bundling stage into a new $\mathrm{Cu}$ can, the total Ta volume fraction (\% Ta) decreases from $66.2 \%$ at $N=1$ down to $7.5 \%$ at $N=85^{4}$.

\section{Microstructural characterization}

\subsection{Texture analysis}

The development of the macroscopic texture during the repeated hot extrusion and cold drawing stages was first studied using XRD measurements. The local texture of $\mathrm{Cu}$ and $\mathrm{Ta}$ was also investigated using TEM selected area electron diffraction (TEM SAED) as discussed in Section 3.2.

XRD patterns were obtained using a Seifert diffractometer. The texture developed in the drawing axis direction was characterized by standard $\theta-2 \theta$ scans using $\mathrm{Cu} \mathrm{K \alpha}$ radiation. $\theta-2 \theta$ scans were obtained from cross-sections of specimens taken throughout the fabrication stages.

A useful way to characterize the formation of fiber textures is to compute the integrated intensities of the Bragg peaks from $\theta-2 \theta$ scans and to compare them to each other in terms of the ratio of the integrated intensity $I(h k l)$ of the $(h k l)$ peaks to the integrated intensity of the dominant peak: in our case $I(h k l) / I\left(\begin{array}{lll}1 & 1 & 0\end{array}\right)$ for Ta and $I(h k l) / \mathrm{I}\left(\begin{array}{lll}1 & 1 & 1\end{array}\right)$ for $\mathrm{Cu}$. Figs. 2(a) and (b) show the evolution of the texture in the Ta fibers and in the $\mathrm{Cu}$ matrix during processing at each stage, after hot extrusion and after heavy drawing, using the most significant Bragg peaks. In addition, data for annealed polycrystalline materials (standard $\mathrm{Ta}$ and standard $\mathrm{Cu}$ ) are added to these plots for comparison.

For the Ta fibers (Fig. 2(a)), we notice that from the first stage and throughout the fabrication process, the integrated intensities of the $\left(\begin{array}{llll}2 & 0 & 0\end{array}\right)_{\mathrm{Ta}}$ and $\left(\begin{array}{lll}2 & 1 & 1\end{array}\right)_{\mathrm{Ta}}$ diffraction

Table 1

Dimensional characteristics of a selection of $\mathrm{Cu} / \mathrm{Ta}$ conductors

\begin{tabular}{|c|c|c|c|c|c|c|c|c|c|c|c|}
\hline Sample & $N$ & $d(\mathrm{~mm})$ & $\% \mathrm{Ta}$ & $d_{\mathrm{Ta}}(\mathrm{nm})$ & $d_{\mathrm{Cu}-0}(\mathrm{~nm})$ & $d_{\mathrm{Cu}-1}(\mu \mathrm{m})$ & $d_{\mathrm{Cu}-2}(\mu \mathrm{m})$ & $d_{\mathrm{Cu}-3}(\mu \mathrm{m})$ & $d_{\mathrm{Cu}-4}(\mathrm{~mm})$ & RA (\%) & $\eta$ \\
\hline a1 & 1 & 15 & 66.2 & $1.22 \times 10^{7}$ & $1.4 \times 10^{6}$ & - & - & - & - & $\approx 0(\mathrm{E})$ & $\overline{2.1}$ \\
\hline a2 & & $3.35^{*}$ & 66.2 & $2.86 \times 10^{6}$ & $6.53 \times 10^{5}$ & 4000 & - & - & - & 99.3 & 5 \\
\hline a3 & 85 & 18 & 41.5 & $1.2 \times 10^{6}$ & $2.73 \times 10^{5}$ & 1670 & - & - & - & $\approx 0(\mathrm{E})$ & 6.7 \\
\hline a4 & & $3.35^{*}$ & 41.5 & $2.33 \times 10^{5}$ & $5.3 \times 10^{4}$ & 653 & 4000 & - & - & 99.3 & 10 \\
\hline a5 & $85^{2}$ & 18 & 23.4 & $9.7 \times 10^{4}$ & $2.2 \times 10^{4}$ & 273 & 1670 & - & - & $\approx 0(\mathrm{E})$ & 11.8 \\
\hline a6 & & $3.35^{*}$ & 23.4 & $1.9 \times 10^{4}$ & 4350 & 53 & 653 & 4000 & - & 99.3 & 15 \\
\hline a7 & $85^{3}$ & 18 & 13.2 & $7.97 \times 10^{4}$ & 1820 & 22 & 273 & 1670 & - & $\approx 0(\mathrm{E})$ & 16.8 \\
\hline a8 & & $3.35^{*}$ & 13.2 & 1550 & 355 & 4 & 53 & 653 & - & 88.2 & 20 \\
\hline a9 & & 2.41 & 13.2 & 1060 & 244 & 2.99 & 36.6 & 224 & - & 94.4 & 20.8 \\
\hline a10 & & 1.83 & 13.2 & 810 & 185 & 2.27 & 27 & 170 & - & 96.69 & 21.3 \\
\hline a11 & & 1.398 & 13.2 & 619 & 144 & 1.76 & 21.6 & 130 & - & 98.13 & 21.9 \\
\hline a12 & & 1.293 & 13.2 & 572 & 131 & 1.6 & 19.6 & 120 & - & 98.4 & 22 \\
\hline a13 & $85^{4}$ & 18 & 7.5 & 650 & 149 & 1.82 & 22.3 & 273 & 1.40 & $\approx 0(\mathrm{E})$ & 21.8 \\
\hline
\end{tabular}

$N$, filament number; $d$, wire total diameter (*hexagonal section); \%Ta, total Ta volume fraction; $d_{\mathrm{Ta}}$, theoretical Ta filament diameter; $d_{\mathrm{Cu}-i}$, theoretical width of $\mathrm{Cu}-i$ channel; RA, reduction in area (see text); E, sample taken after hot extrusion; $\eta$, total logarithmic true strain (see text). 

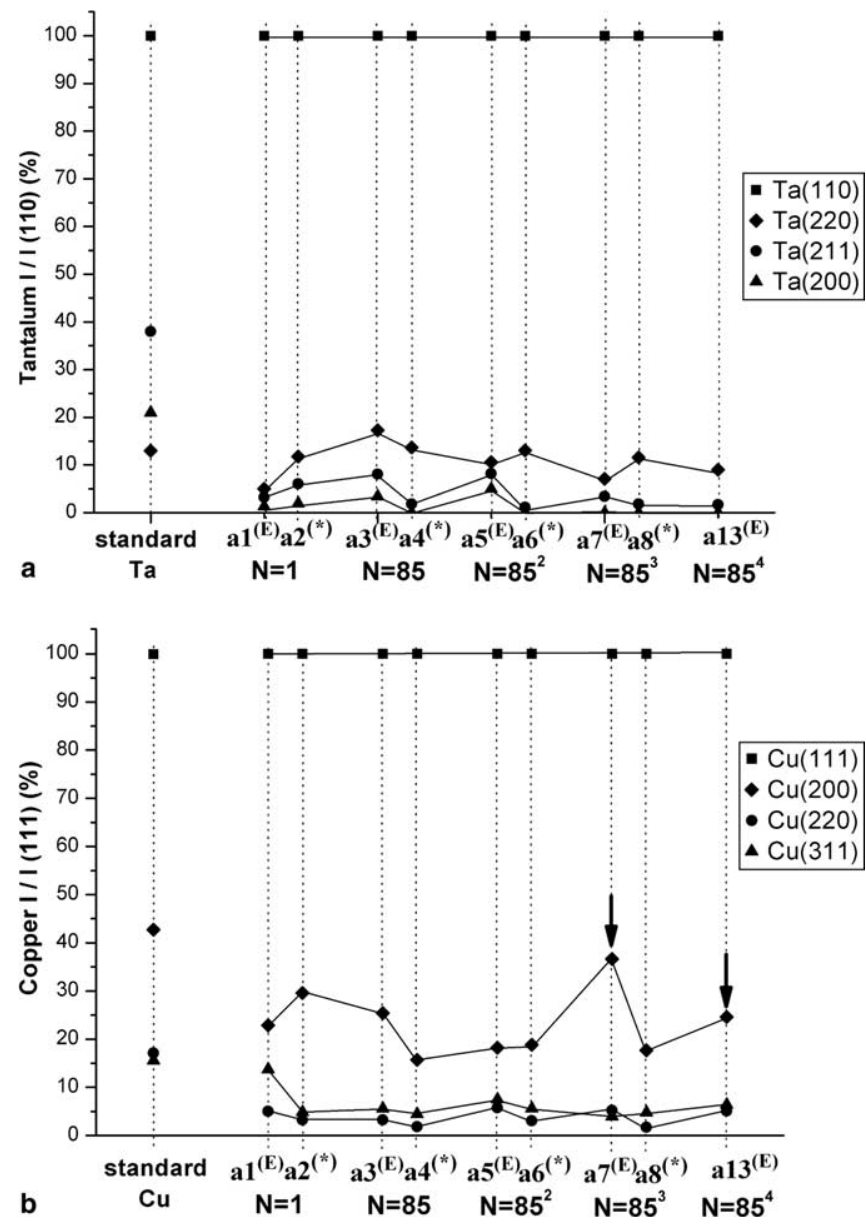

Fig. 2. Ratio of integrated intensities of the Bragg peaks from $\theta-2 \theta$ XRD scans on $\mathrm{Cu} / \mathrm{Ta}$ nanofilamentary wires at different fabrication stages (hot extruded or heavily cold drawn). Development of texture appears: (a) in $\mathrm{Ta}$ and (b) in $\mathrm{Cu}$ (solid lines are guides to the eyes) (*hexagonal section; $\mathrm{E}$, sample taken after hot extrusion).

peaks markedly decrease and the integrated intensities of the $\left(\begin{array}{lll}1 & 1 & 0\end{array}\right)_{\mathrm{Ta}}$ and $\left(\begin{array}{lll}2 & 2 & 0\end{array}\right)_{\mathrm{Ta}}$ peaks remain strong. This confirms that Ta develops a strong $\langle 110\rangle$ fiber texture parallel to the wire axis during the fabrication process as reported in the literature for heavily drawn bcc metals [24]. In particular, the same result was obtained with drawn $\mathrm{Cu} / \mathrm{Nb}$ nanofilamentary wires [25].

For the $\mathrm{Cu}$ matrix (Fig. 2(b)), the ratio of the integrated intensities of the $\left(\begin{array}{lll}2 & 0 & 0\end{array}\right)_{\mathrm{Cu}}$ to $\left(\begin{array}{lll}1 & 1 & 1\end{array}\right)_{\mathrm{Cu}}$ diffraction peaks noticeably increase for the a7 and a13 samples after hot extrusion (data points marked with an arrow). Several $\theta-2 \theta$ scans were carried out and confirmed this result. Therefore, $\mathrm{Cu}$ exhibits two texture components along the wire axis: a major $\left\langle\begin{array}{llll}1 & 1 & 1\end{array}\right\rangle$ component and a $\langle 200\rangle$ component which remains significant throughout the fabrication process.

It is usually observed that the $\langle 200\rangle$ component in fcc metals tends to disappear during drawing leading to a single $\left\langle\begin{array}{llll}1 & 1 & 1\end{array}\right\rangle$ texture in heavily drawn fcc metals [24]. This was indeed observed during the fabrication process of $\mathrm{Cu} / \mathrm{Nb}$ nanofilamentary wires [25] but not during the fabrication of $\mathrm{Cu} / \mathrm{Ta}$ nanofilamentary wires studied in the present paper. However, it was recently reported that the major $\left\langle\begin{array}{llll}1 & 1 & 1\end{array}\right\rangle$ and the minor $\langle 200\rangle$ components, developed as a duplex texture in axisymmetrically deformed fcc metals, change to strong $\langle 200\rangle$ components after recrystallization heat treatments $[10,26]$. It is worth mentioning that after each bundling stage, the $\mathrm{Cu} / \mathrm{Ta}$ conductors are hot extruded after annealing at $700{ }^{\circ} \mathrm{C}$ : the $\mathrm{Cu}$ matrix is then fully recrystallized. Therefore, the origin of the rather strong $\langle 200\rangle$ texture could be explained by the annealing and hot extrusion stages. As suggested in Ref. [26] according to the strain energy release maximization model, the $\langle 200\rangle$ oriented grains might retain their texture while the $\left\langle\begin{array}{llll}1 & 1 & 1\end{array}\right\rangle$ grains tend to the $\langle 200\rangle$ orientation via high-angle boundary migration. However, it appears important to study thoroughly the texture development during the elaboration of the $\mathrm{Cu} / \mathrm{Ta}$ nanofilamentary wires, since there is no clear correlation between the fraction of the $\langle 200\rangle \mathrm{com}-$ ponent and the strain state of the conductors. To do so, complete pole figures should be obtained.

In summary, this study revealed that Ta develops a $\left\langle\begin{array}{llll}1 & 1 & 0\end{array}\right\rangle$ texture parallel to the wire axis while $\mathrm{Cu}$ exhibits a duplex texture with a $\left\langle\begin{array}{llll}1 & 1 & 1\end{array}\right\rangle$ major orientation and a secondary $\langle 200\rangle$ component along the wire axis, which is not observed in the $\mathrm{Cu} / \mathrm{Nb}$ system.

\subsection{Microstructure analysis}

\subsubsection{Sample preparation}

TEM specimens were prepared by mechanical polishing to a thickness of $80 \mu \mathrm{m}$ followed by a tripod-polishing step. Then, samples were argon ion milled with a Gatan Model dual-gun ion mill at liquid-nitrogen temperature using an accelerating voltage of $5 \mathrm{kV}$ and a $14^{\circ}$ tilt.

\subsubsection{General results}

TEM observations were carried out using a JEOL $200 \mathrm{CX}$ instrument operating at $200 \mathrm{kV}$. Figs. 3-5 present the microstructures of a10, a12 and a13 samples for both transverse and longitudinal sections. In bright-field images, Ta appears darker than $\mathrm{Cu}$. This is explained by the fact that Ta is a much heavier element. Moreover, due to the difference in hardness between $\mathrm{Cu}$ and $\mathrm{Ta}$, the $\mathrm{Cu}$ regions are thinner than the Ta regions.

On the transverse section, the Ta fibers appear flattened and curled (Figs. 3(a-c), 4(a) and (b) and 5(a)) containing nanograins with sizes ranging from 100 to $200 \mathrm{~nm}$ (Figs. $3(\mathrm{c})$ and 5(b)) which is similar to the size of dislocation cells observed in heavily cold worked $\mathrm{Nb}$. These nanograins are thus due to the transformation of cell walls into subgrain boundaries then into grain boundaries during intensive plastic deformation $(\eta>20)$ as a result of dynamic recrystallization coupled to static recovery during intermediate annealing.

Because of the multiscale structure, different sizes of $\mathrm{Cu}$ channels exist in $\mathrm{Cu} / \mathrm{Ta}$ wires. In the largest $\mathrm{Cu}$ channels (Figs. 3(d) and (e) and 4(c)), grains both in micrometer 
and in nanometer (200-400 $\mathrm{nm}$ ) ranges are elongated along the drawing direction and have a high dislocation density. Dislocation substructures are shown in Figs. 3(d) and 4(c). These types of cells with dislocation walls and low internal dislocation density are characteristics of heavily deformed metals.

Fig. 3(e) shows two different SAED patterns from a same channel of $\mathrm{Cu}$ : as was observed in the XRD investigation, the $\mathrm{Cu}$ exhibits both $\left\langle\begin{array}{llll}1 & 1 & 1\end{array}\right\rangle$ and $\langle 200\rangle$ texture components. However, determination of a clear correlation between the size of $\mathrm{Cu}$ grains and this duplex texture was not possible by TEM observations.

The finest $\mathrm{Cu}$ channels are composed of single grains elongated along the drawing axis with their grain boundary perpendicular to the wire axis as indicated by arrows in Figs. 3(f) and (g). These $\mathrm{Cu}$ grains are longer than $3 \mu \mathrm{m}$.

In Fig. 4(b), the indexed SAED pattern from a Ta + $\mathrm{Cu}-0$ zone shows the presence of a strong $\left\langle\begin{array}{llll}1 & 1 & 0\end{array}\right\rangle_{\mathrm{Ta}}$ texture component for the $\mathrm{Ta}$ and characterizes the texture of the interfilamentary $\mathrm{Cu}-0$ as composed of $\left\langle\begin{array}{llll}1 & 1 & 1 & \rangle_{\mathrm{Cu}} \\ \text { and }\end{array}\right.$ $\langle 200\rangle_{\mathrm{Cu}}$ components but also of a $\langle 220\rangle_{\mathrm{Cu}}$ component $\left(\begin{array}{lll}\{ & 1 & 1\end{array}\right\}_{\mathrm{Cu}}$ reflections), although it is considered as a weak orientation from the XRD study.

The presence of these three $\mathrm{Cu}$ texture components $\left(\begin{array}{llll}1 & 1 & 1\end{array}\right\rangle,\left\langle\begin{array}{lll}2 & 0 & 0\end{array}\right)$ and $\left\langle\begin{array}{lll}2 & 2 & 0\end{array}\right)$ ) in this disturbed area, characterized by interfolded Ta ribbons, seems to show that the $\mathrm{Ta}$ constrains the $\mathrm{Cu}$ matrix in such a way that it essentially deforms to ensure the deformation compatibility with Ta without regard to its usual texture development.

Because of the highly irregular section of the Ta fibers, on longitudinal micrographs the same fiber can be seen as split into several strips, all parallel to the drawing direction. Thus, the deduction of the size of $\mathrm{Cu}$ must be done carefully from measurements of longitudinal micrographs.

Nevertheless, the width of the distinctive $\mathrm{Cu}$ channels is generally in good agreement with the theoretical dimensions listed in Table 1.
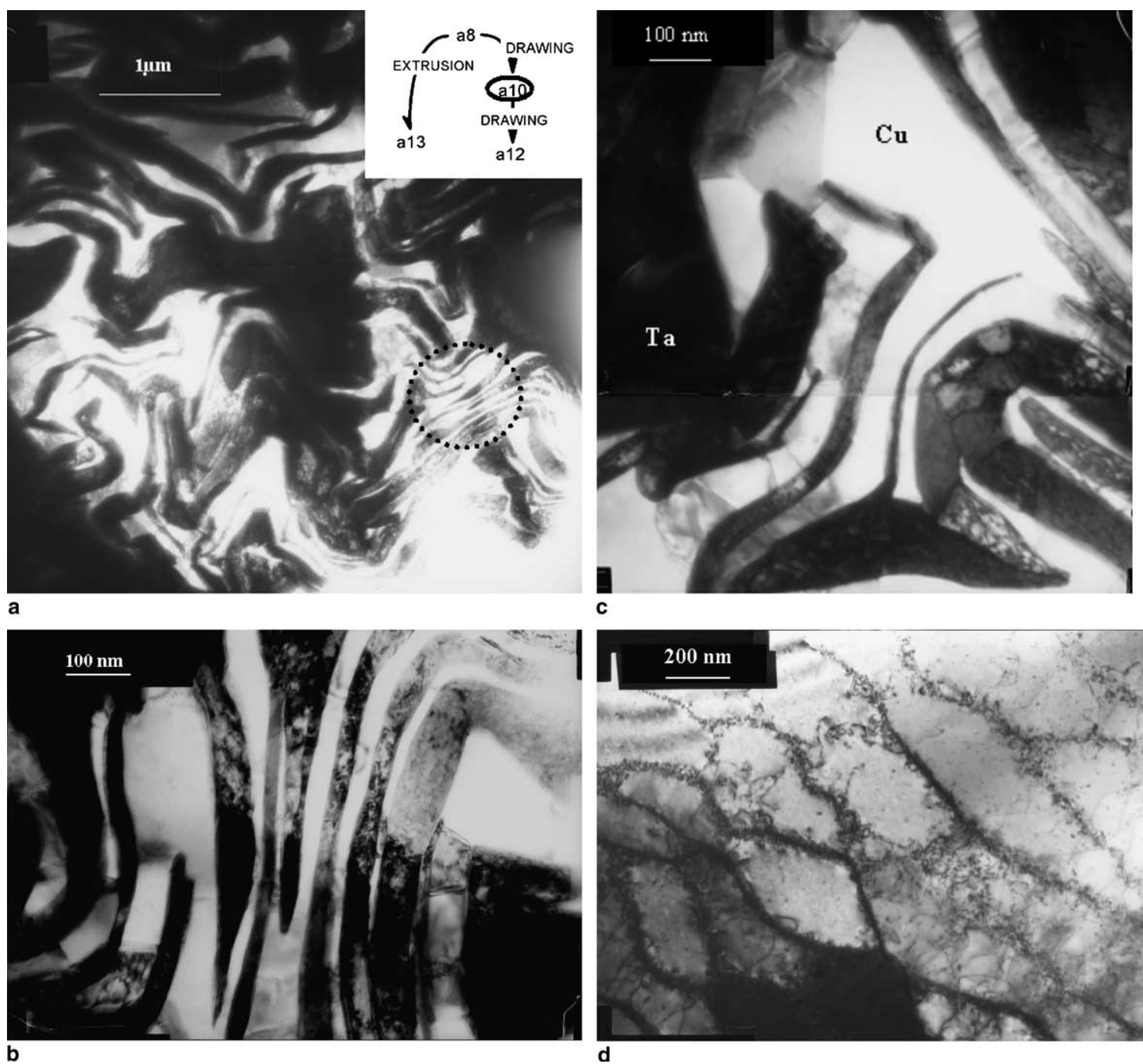

c

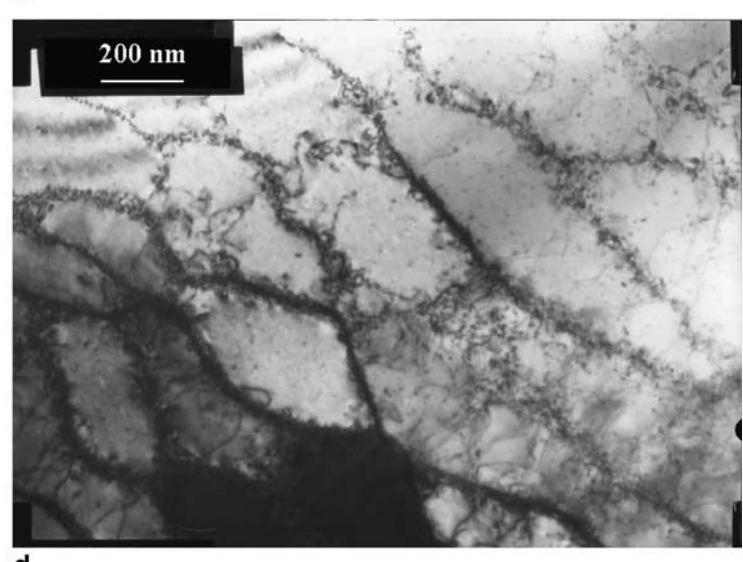

Fig. 3. Bright-field TEM images of a10 specimen $\left(N=85^{3}, d=1.8 \mathrm{~mm}\right)$. Transverse section: (a) ribbon-like shape of the Ta filaments; (b) close-up of the dotted circle in (a); (c) grains in Ta fibres; (d) dislocation cell structure in $\mathrm{Cu}$; (e) SAED patterns of a Cu-1 channel: $\langle 200\rangle$ above and $\langle 111\rangle$ below. Longitudinal section: (f) $\mathrm{Cu}$ channels composed of successions of single grains; (g) example of transverse grain boundary. 


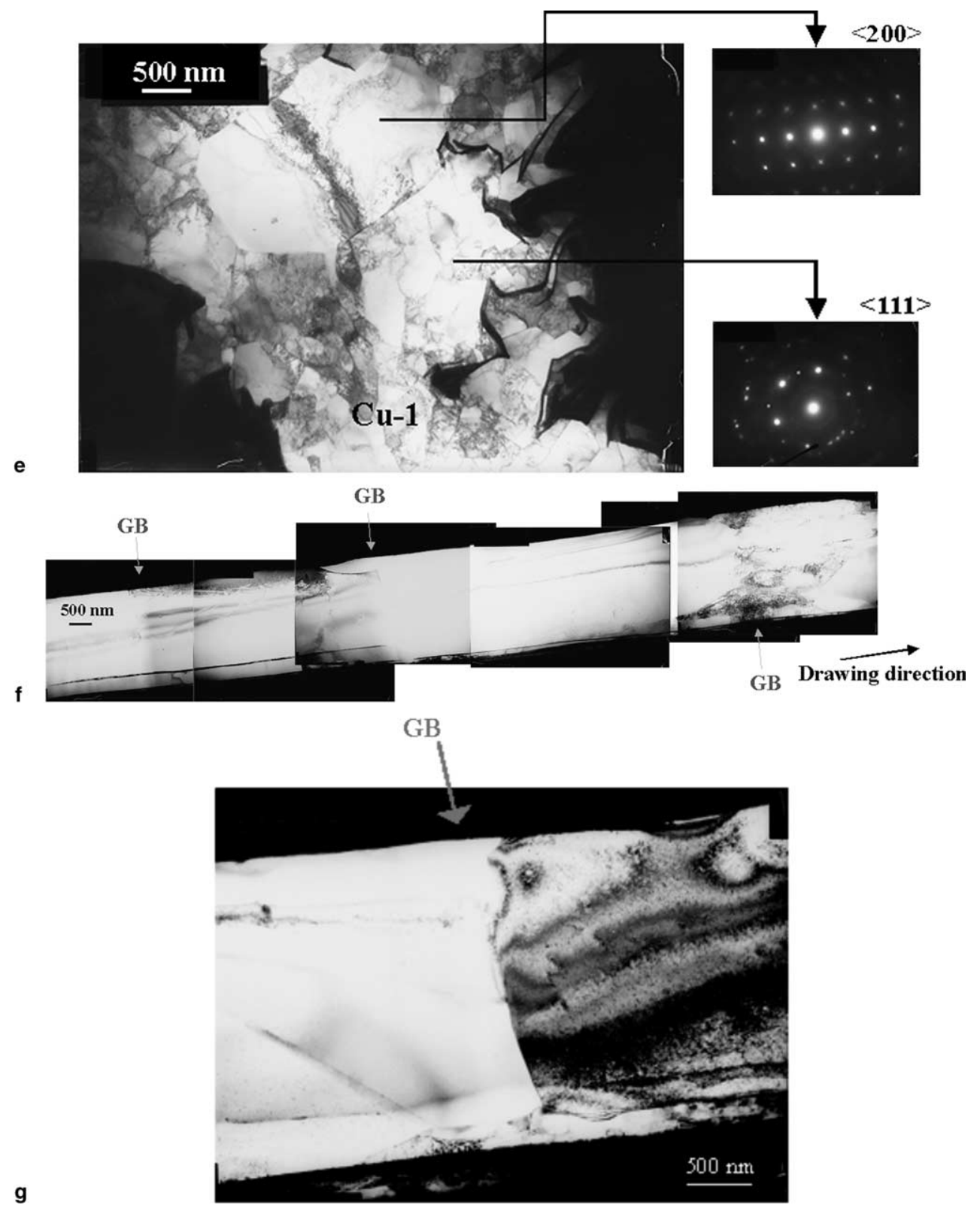

Fig. 3 (continued)

\subsubsection{Geometry of the fibers}

The observed ribbon-like structure of the Ta filaments (Figs. 1, 3(a-c), 4(a) and (b) and 5(a)) is characteristic of the bcc deformation mode when heavily drawn [24]. Bcc crystals with $\left\langle\begin{array}{llll}1 & 1 & 0\end{array}\right)$ drawing texture have slip systems orientated in such a way that plane-strain deformation is energetically more favorable than axisymmetric deformation (only two of the four $\left\langle\begin{array}{llll}1 & 1 & 1\end{array}\right\rangle$ directions are orientated favorably to accommodate extension parallel to the fiber axis). Consequently, the fibers develop elliptical cross-sections normal to the wire axis resulting in the ribbon-like shape.

Such a shape was also observed for $\mathrm{Nb}$ fibers in $\mathrm{Cu} / \mathrm{Nb}$ nanofilamentary wires but to a lesser extent. This could be due to the larger difference in the mechanical behavior between $\mathrm{Cu}$ and $\mathrm{Ta}$, where the hard $\mathrm{Ta}$ is surrounded by softer $\mathrm{Cu}$ and hence is "free" to deform in the more energetically favorable configuration. The result is a rather inhomogeneous distribution in the Ta size. Similar microstructures are observed in heavily drawn "in situ" $\mathrm{Cu} / \mathrm{Fe}$ composites, where $\mathrm{Cu}$ and $\mathrm{Fe}$ have also very different shear moduli $[20,21]$ (it must be stressed here that even in "in situ" $\mathrm{Cu} / \mathrm{Nb}$ composites rather strong curling is observed, resulting from the initial heterogeneous dendritic structure; this is not the case in the "continuous" $\mathrm{Cu} / \mathrm{Nb}$ system, with an initial homogeneous filamentary structure).

Consequently, the definition of a diameter value becomes problematic. SEM and TEM images from crosssections of samples a8, a10, a12 and a13 were examined to obtain reliable values for the microstructural dimensions: the results of the estimation of the effective filament 

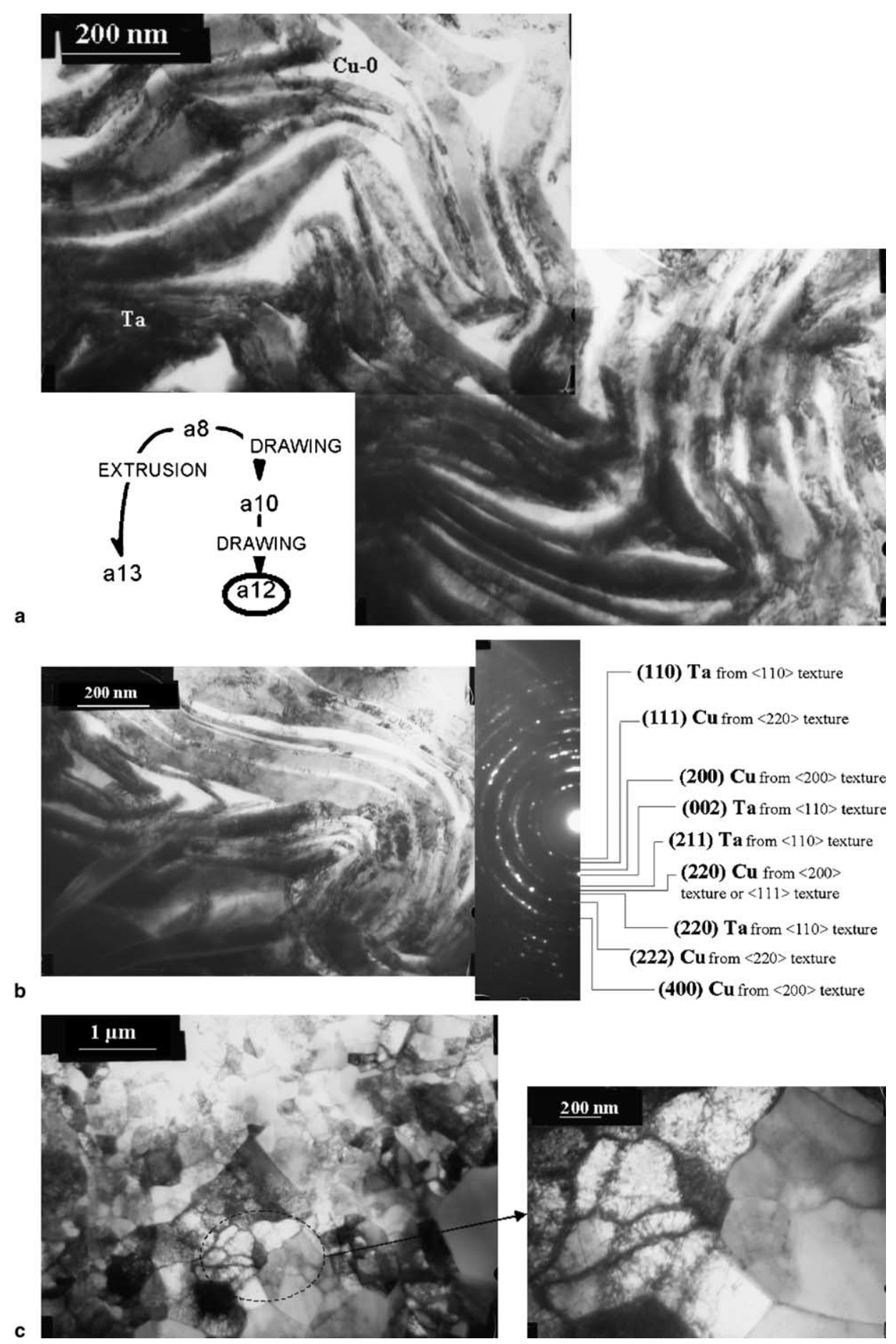

Fig. 4. Bright-field TEM images of transverse section from specimen a12 $\left(N=85^{3}, d=1.293 \mathrm{~mm}\right)$. (a) Ribbon-like shape of the Ta filaments; (b) close-up of Ta ribbons $+\mathrm{Cu}-0$ zones and associated SAED pattern; (c) different grain size in a large Cu channel and close-up of dislocation cell structure.

thickness, $t_{\mathrm{effTa}}$, are summarized in Table 2 . As the dispersion of $t_{\text {effTa }}$ is different for each sample, an average value is defined for small-dispersion samples (a8, a12 and a13). When the dispersion is too wide (sample a10), the average value has no microstructural sense, thus $t_{\text {eff Ta }}$ is not defined. The filament evolution characterized by the effective thickness (replacing the theoretical Ta diameter) will be taken into account in the following sections.
Fig. 6 shows the microstructural evolution during hot extrusion and cold drawing by plotting the effective thickness (and its dispersion) versus the theoretical Ta diameter. During hot extrusion (conductor a8 to conductor a13), where a large strain is applied through only one deformation step, the thickness of the Ta ribbons and its dispersion reduces in a rather homogeneous manner. In contrast, after repeated cold drawing steps $(8$ passes between samples a8 


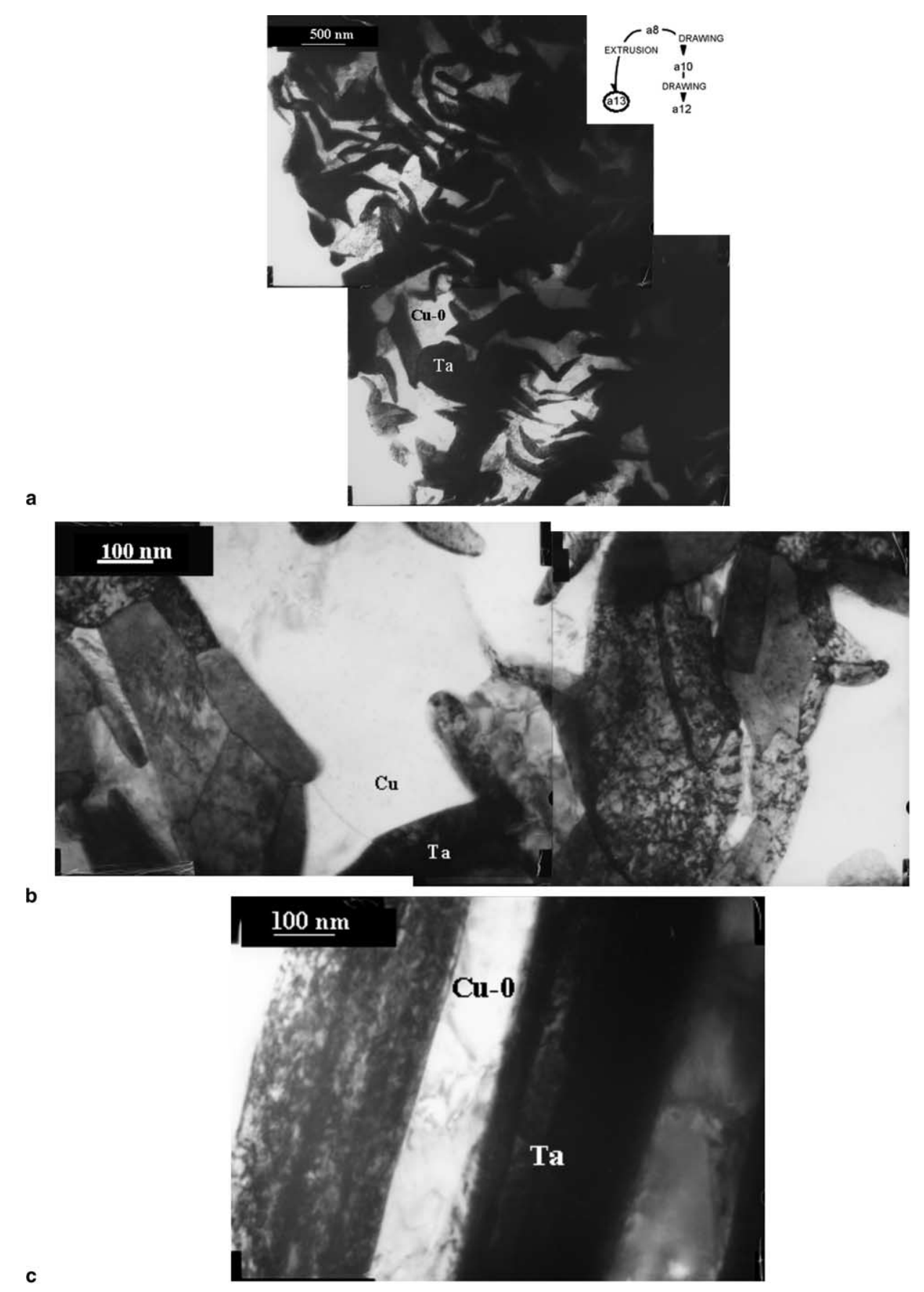

Fig. 5. Bright-field TEM images of $(\mathrm{a}, \mathrm{b})$ transverse and (c) longitudinal sections from specimen a13 $\left(N=85^{4}\right.$ after hot extrusion) showing Ta fibres surrounded by $\mathrm{Cu}$.

and a10, 5 passes between samples a10 and a12), the reduction of the Ta dimension does not follow the same trend: the dispersion in ribbon thickness becomes very large for the a10 sample, while, after significant amount of strain (sample a12), the Ta ribbons flatten and rotate in transverse directions and the degree of microstructural refinement increases with a fairly small spread of values. This is evidence that the so-called "curling" phenomenon is induced by the repeated activation of only a few slip systems in the Ta fibers associated with repeated rotation and folding of the $\mathrm{Ta}+\mathrm{Cu}-0$ zones. Such a phenomenon mainly occurs during multiple drawing steps but does not have time to develop during single-step extrusion.

It is also interesting to note that samples a10 and a12 have the same lower bound thickness value showing a stabilization of the ribbon thickness at about $20 \mathrm{~nm}$; this value could be considered as a critical Ta thickness corresponding to a plastic deformation limit as already observed during the drawing of $\mathrm{Cu} / \mathrm{Fe}$ in situ composites [20]. This limit could be associated with the occurrence of internal 
Table 2

Estimation of the effective Ta thickness observed for a selection of $\mathrm{Cu} / \mathrm{Ta}$ conductors

\begin{tabular}{lllllll}
\hline & $N$ & $\begin{array}{l}\text { Size of the } \\
\text { conductor }(\mathrm{mm})\end{array}$ & $\begin{array}{l}\text { Observation } \\
\text { technique }\end{array}$ & $\begin{array}{l}\text { Theoretical Ta } \\
\text { diameter } d_{\mathrm{Ta}}\end{array}$ & $\begin{array}{l}\text { Range of measured } \\
\text { Ta thickness values }\end{array}$ & $\begin{array}{l}\text { Effective Ta thickness } \\
(\text { average }) t_{\text {effTa }}(\mathrm{nm})\end{array}$ \\
\hline a8 & $85^{3}$ & $h=3.35$ & SEM & $1.55 \mu \mathrm{m}$ & {$[430 \mathrm{~nm}-1.14 \mu \mathrm{m}]$} & 812 \\
a10 & $85^{3}$ & $d=1.83$ & TEM & $810 \mathrm{~nm}$ & {$[24 \mathrm{~nm}-820 \mathrm{~nm}]$} & Not accurate \\
a12 & $85^{3}$ & $d=1.293$ & TEM & $572 \mathrm{~nm}$ & {$[21 \mathrm{~nm}-145 \mathrm{~nm}]$} & 72 \\
a13 & $85^{4}$ & $d=18$ & TEM & $650 \mathrm{~nm}$ & {$[92 \mathrm{~nm}-461 \mathrm{~nm}]$} & 253 \\
\hline
\end{tabular}

$h$, hexagonal section.

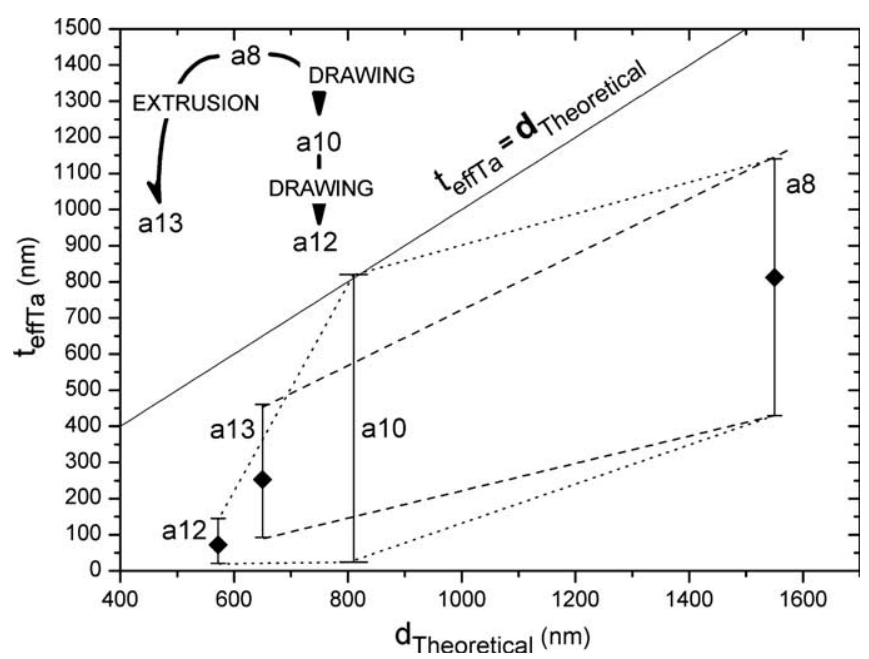

Fig. 6. Effective thickness, $t_{\mathrm{eff} T a}$ (and its dispersion) versus the theoretical Ta diameter $d_{\text {Ta }}$. Differences of microstructural evolution during hot extrusion (dashed line) and drawing (dotted line) are observed (see text).

fractures during the final drawing stages that prevent one from obtaining samples finer than sample a12. In addition, the space restriction characterized by very narrow interfilamentary distances makes the co-deformation of the ribbons and the matrix more difficult, as observed in Figs. 4(a) and (b) (sample a12) where $\mathrm{Cu}-0$ islands were formed (100 nm in size). Therefore, the elongation during drawing of the very fine-diameter conductors seems to be accommodated by the $\mathrm{Cu}$ matrix, through complex deformation (plasticity and grain boundary sliding) rather than true codeformation of the system.

\section{Electrical characterization}

The electrical resistivity of $\mathrm{Cu} / \mathrm{Ta}$ conductors was measured using the classic four-probe technique with a maximum current of $100 \mathrm{~mA}$ to avoid heating of the wires. The resistivity values for samples a9 $(d=2.41 \mathrm{~mm})$, a10 $(d=1.83 \mathrm{~mm})$ and a11 $(d=1.398 \mathrm{~mm})$ at $77 \mathrm{~K}$ are, respectively, $0.375,0.382$ and $0.401 \mu \Omega \mathrm{cm}$. The decrease of the electrical conductivity with a reduction in diameter results from the increase of dislocation density, the dislocations being scattering centers for electrons, and also from the size reduction of the finest $\mathrm{Cu}$ channels the thickness of which becomes comparable to the mean free path of electrons at $77 \mathrm{~K}(\sim 200 \mathrm{~nm})$. Since these channels become poor con- ductors, most of the current is transported in the outer $\mathrm{Cu}$ channels. Nevertheless, the resistivity remains smaller than twice that of annealed $\mathrm{Cu}(0.2 \mu \Omega \mathrm{cm})$ and therefore satisfies the requirements for magnet applications.

\section{Mechanical characterization}

\subsection{Experimental procedure}

This section describes the mechanical testing of the $\mathrm{Cu} / \mathrm{Ta}$ wires via macroscopic tensile tests as well as a nanoindentation study of the local mechanical properties with the indentation axis parallel to the filament axis. Segments of the nanocomposite conductors were cut using a metallographic saw and embedded in epoxy resin so that the crosssectional surface of the wire can be perfectly perpendicular to the indenter axis. The samples were then mechanically polished. Nanoindentation experiments were performed using a nanohardness tester (CSM Instruments, SA) with a diamond Berkovich indenter (three-sided pyramid). A maximum load of $5 \mathrm{mN}$ was applied with loading and unloading rates of $10 \mathrm{mN} / \mathrm{min}$ and a holding time of $10 \mathrm{~s}$ at maximum load. Hardness was determined from indentation load-displacement data using the Oliver-Pharr method [27].

A wide range of data for each phase was obtained: from the largest $\mathrm{Cu}-4$ channels to the nanocomposite regions (here "nanocomposite regions" refers to the nanostructured multiphase regions).

\subsection{Results}

Different samples from the $\mathrm{Cu} / \mathrm{Ta}$ system were tested and compared to the $\mathrm{Cu} / \mathrm{Nb}$ system tested in previous studies [15]. Table 3 presents the characteristics of the $\mathrm{Cu} / \mathrm{Ta}$ and $\mathrm{Cu} / \mathrm{Nb}$ nanofilamentary wires and the average hardness $H$ measured in the nanocomposite regions. The indents in these regions cover $\mathrm{Ta}+\mathrm{Cu}-0$ or $\mathrm{Nb}+\mathrm{Cu}-0$ according to the system tested. $X_{\mathrm{nTa}}, X_{\mathrm{nNb}}$ and $X_{\mathrm{nCu}}$ are therefore the local volume fractions of $\mathrm{Ta}, \mathrm{Nb}$ or $\mathrm{Cu}$ in the indented zones.

The mechanical properties of the individual phases in the $\mathrm{Cu} / \mathrm{Ta}$ nanostructured conductors are illustrated in Fig. 7(a), which shows, in a $\log -\log$ plot, the evolution of the hardness $H$ of the tested zones versus the phase dimension $d_{\alpha}$. The size parameter $d_{\alpha}$ corresponds to the 
Table 3

Dimension, hardness data and deviation from ROM values of nanocomposite zones tested in $\mathrm{Cu} / \mathrm{Ta}$ and $\mathrm{Cu} / \mathrm{Nb}$ conductors

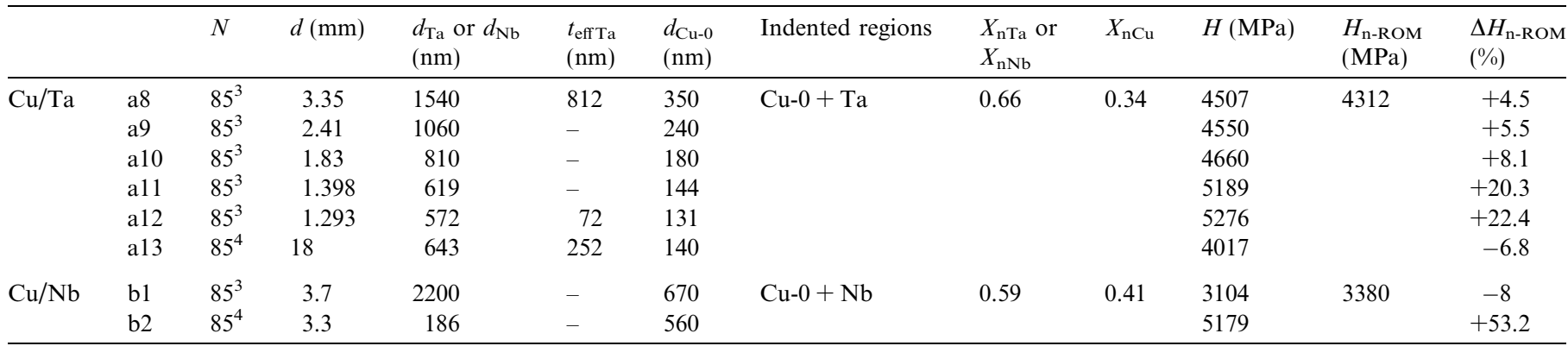

$X_{\alpha}$, local volume fraction of $\alpha$ phase; $H$, averaged nanohardness value; $H_{\mathrm{n}-\mathrm{ROM}}$, hardness from the nano-ROM (see text); $\Delta H_{\mathrm{n}-\mathrm{ROM}}$, deviation from $\mathrm{n}$ ROM (see text)
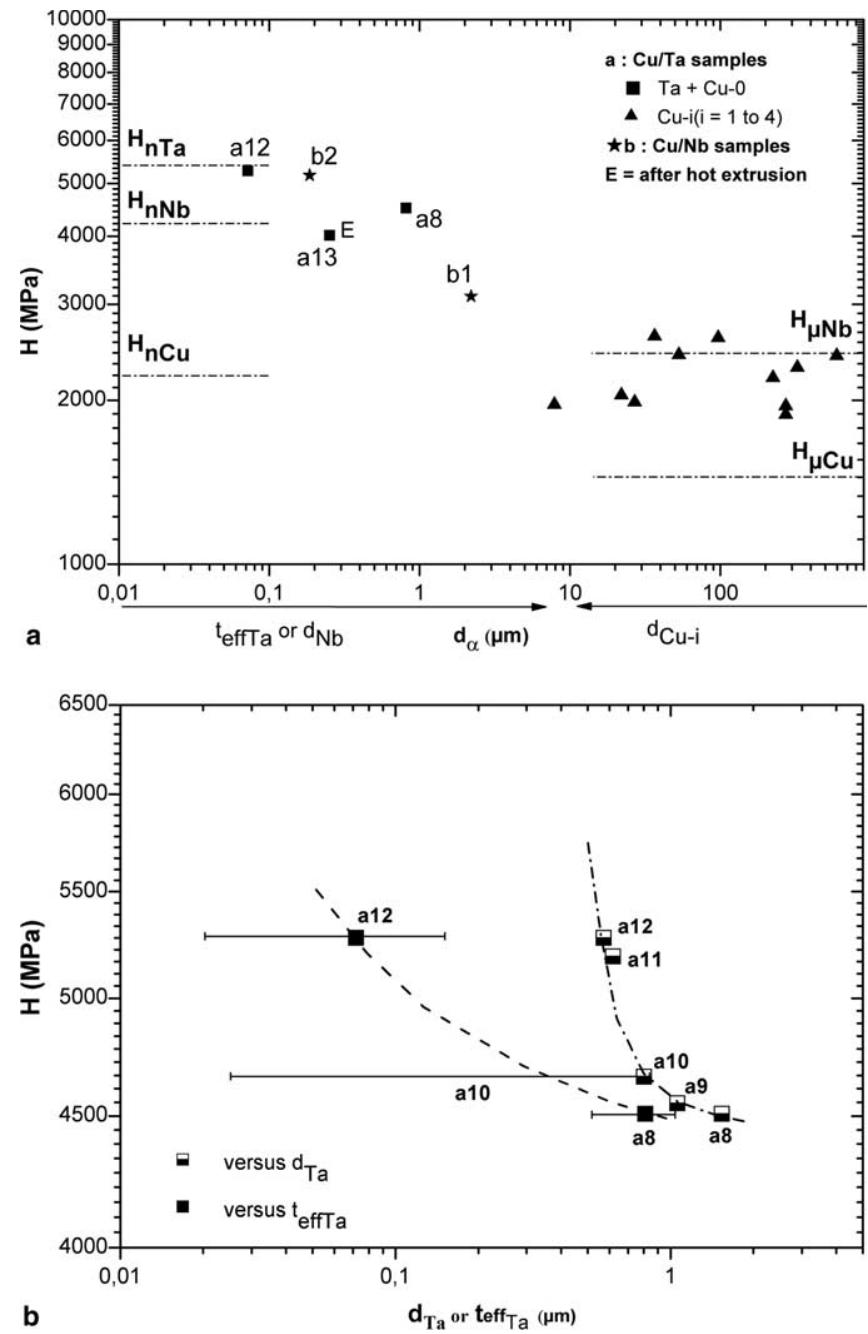

Fig. 7. (a) Hardness evolution versus $d_{\alpha}$ for $\mathrm{Cu} / \mathrm{Ta}$ samples compared with $\mathrm{Cu} / \mathrm{Nb}$ samples. $\alpha$ is the $\mathrm{Cu}-i(i=1-4)$ phase in the micrometer range; $\alpha$ is the $\mathrm{Ta}$ or $\mathrm{Nb}$ phase for the indented nanocomposite regions. Note that for $\mathrm{Cu} / \mathrm{Ta}, d_{\alpha}$ is the "effective" size of the Ta ribbons (see text). $H_{\alpha}=$ hardness literature data of $\alpha$ phase, in bulk coarse-grain $\left(H_{\mu \alpha}\right)$ or bulk nanostructured $\left(H_{\mathrm{n} \alpha}\right)$ states. (b) Hardness evolution of $\mathrm{Cu} / \mathrm{Ta}$ samples versus both the theoretical Ta diameter $(\boxminus)$ and the "effective" size of the Ta ribbons

(ם). Dashed and dash-dot lines are guides for the eye. channel width of the $\mathrm{Cu}-i$ phase $(i=1-4)$ in the micrometer range while for the indented nanocomposite regions $d_{\alpha}$ corresponds to the previously defined effective Ta filament thickness, $t_{\mathrm{effT}}$, or to the $\mathrm{Nb}$ filament diameter $d_{\mathrm{Nb}}$. The hardness data of the nanocomposite regions in the $\mathrm{Cu} / \mathrm{Nb}$ system have been included (values in Table 2). The literature hardness data for bulk cold drawn coarsegrain $\mathrm{Nb}$ and $\mathrm{Cu}$ as well as for bulk nanocrystalline $\mathrm{Nb}$ and $\mathrm{Cu}$ have been included in the plot $\left(H_{\mu \mathrm{Nb}}=2.4 \mathrm{GPa}\right.$, $H_{\mu \mathrm{Cu}}=1.6 \mathrm{GPa}$ and $H_{\mathrm{nNb}}=4.2 \mathrm{GPa}, H_{\mathrm{nCu}}=2.2 \mathrm{GPa}$, respectively). Fig. 7(b) illustrates the effect of the early refinement of the Ta ribbons on the mechanical properties by plotting the hardness evolution in the nanocomposite zones in $\mathrm{Cu} / \mathrm{Ta}$ samples versus both the theoretical diameter $d_{\mathrm{Ta}}$ and the effective thickness $t_{\text {effTa }}$. Guidelines have been added to this plot (dashed and dash-dot lines) to emphasize the increasing trend of the two data sets: it appears that without considering the effective thickness of the Ta ribbons $\left(t_{\text {eff Ta }}\right)$ the size effect on the $\mathrm{Cu} / \mathrm{Ta}$ hardness would clearly be overestimated. The hardness evolution plotted versus the theoretical diameter thus gives inaccurate information for the $\mathrm{Cu} / \mathrm{Ta}$ system.

For samples a8-a12, the hardness of the $\mathrm{Ta}+\mathrm{Cu}-0$ zones increases from 4.5 to $5.2 \mathrm{GPa}$. Sample a13 corresponds to the hot extruded state. The hardness of this sample appears lower because of the high temperature of the extrusion stage $\left(700{ }^{\circ} \mathrm{C}\right)$ that acts as a recrystallization heat treatment. Hence to interpret the evolution of $H$, we must take into account the size, the cold working state and the local composition of the indented zone.

To complete the study of these local properties, UTS data were obtained for $\mathrm{Cu} / \mathrm{Ta}$ and $\mathrm{Cu} / \mathrm{Nb}$ conductors at $293 \mathrm{~K}$ from classic tensile tests. In particular, the UTS for the $\mathrm{Cu} / 13$ vol.\% Ta system reaches $634 \mathrm{MPa}$ for a diameter of $2.41 \mathrm{~mm}$ (sample a9) and $711 \mathrm{MPa}$ for a diameter down to $1.83 \mathrm{~mm}$ (sample a10) with an effective Ta thickness in the $24-820 \mathrm{~nm}$ range. For the $\mathrm{Cu} / 11.7$ vol.\% Nb system, UTS reaches $576 \mathrm{MPa}$ for a conductor diameter of $2 \mathrm{~mm}$ and a $\mathrm{Nb}$ fiber diameter of $830 \mathrm{~nm}$. In both cases, these strengths deviate strongly from the classic ROM results 
calculated considering fully cold worked bulk materials $\left(\sigma_{\text {UTS }}(\mathrm{Cu})=400 \mathrm{MPa}, \sigma_{\mathrm{UTS}}(\mathrm{Nb})=1400 \mathrm{MPa}\right.$ and $\sigma_{\mathrm{UTS}}$ $(\mathrm{Ta})=1800 \mathrm{MPa}): \sigma_{\text {UTS }}(\mathrm{ROM}-\mathrm{Cu} / 13 \% \mathrm{Ta})=586 \mathrm{MPa}$ and $\sigma_{\text {UTS }}(\mathrm{ROM}-\mathrm{Cu} / 11.7 \% \mathrm{Nb})=510 \mathrm{MPa}$.

\subsection{Discussion: comparison with the Cu/Nb system}

In Fig. 7(a), which shows the influence of the size parameter on the mechanical properties, different behaviors are noted:

- For $d_{\alpha}>10 \mu \mathrm{m}$, the hardness data for large $\mathrm{Cu}$ channels are higher than the literature hardness data for bulk coarse-grain $\mathrm{Cu}\left(H_{\mu \mathrm{Cu}}=1.6 \mathrm{GPa}\right)$. This behavior may be a consequence of different effects: (i) the influence of pile-up around $\mathrm{Cu}$ indents that leads to an underestimation of the indenter contact area and thus to an overestimation of the hardness [15,27]; (ii) as observed in the TEM study, the larger $\mathrm{Cu}$ channels are nanostructured. Therefore, hardness data for large $\mathrm{Cu}$ channels tend toward hardness data for nanometre-sized $\mathrm{Cu}$ $\left(H_{\mathrm{nCu}}=2.2 \mathrm{GPa}\right)$.

- For smaller size $\left(d_{\alpha}<10 \mu \mathrm{m}\right)$, we observed an increase of the hardness in the nanocomposite regions.

In a previous study of $\mathrm{Cu} / \mathrm{Nb}$ multifilamentary conductors, a threshold was also observed at $10 \mu \mathrm{m}$, below which strengthening becomes important. This strengthening was shown to be linked to a restriction of the dislocation mobility by the microstructure dimension associated with impenetrable $\mathrm{Cu} / \mathrm{Nb}$ interfaces [15]. These phenomena could be also responsible for the hardness evolution observed in the $\mathrm{Cu} / \mathrm{Ta}$ multifilamentary conductors.

Fig. 8 illustrates the deviation of the hardness from the nano-ROM (n-ROM) values:

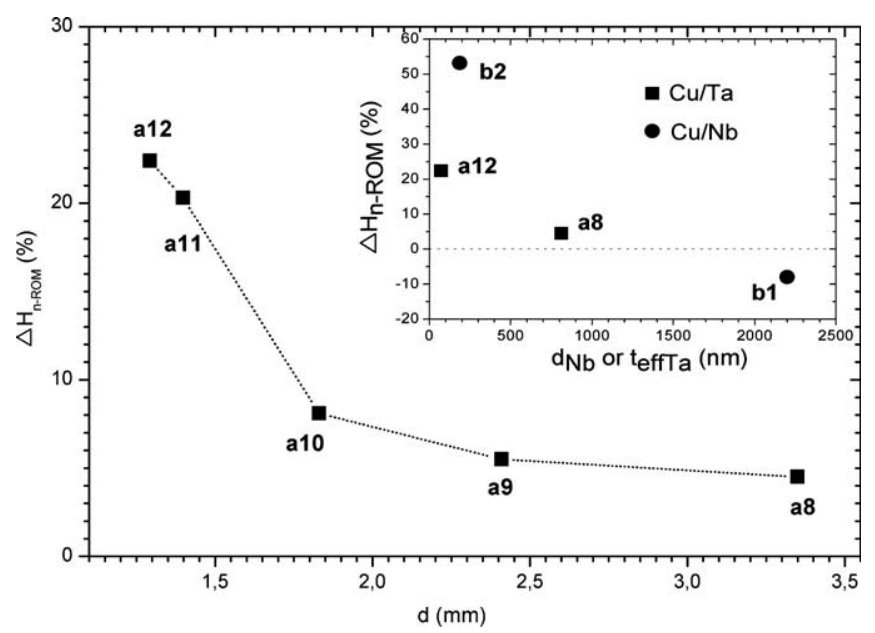

Fig. 8. Deviation $\Delta H_{\mathrm{n}-\mathrm{ROM}}(\%)$ of the hardness $H$ from the nanostructured material ROM hardness $\left(H_{\mathrm{n}-\mathrm{ROM}}\right)$ versus the conductor diameter $d$ for $\mathrm{Cu} / \mathrm{Ta}$ conductors. The inset shows the deviation $\Delta H_{\mathrm{n}-\mathrm{ROM}}(\%)$ of the hardness from $H_{\mathrm{n}-\mathrm{ROM}}$ versus $d_{\mathrm{Nb}}$ or $t_{\mathrm{effTa}}$ for $\mathrm{Cu} / \mathrm{Ta}$ and $\mathrm{Cu} / \mathrm{Nb}$ conductors.
$\Delta H_{\mathrm{n}-\mathrm{ROM}}=\left(H-H_{\mathrm{n}-\mathrm{ROM}}\right) / H_{\mathrm{n}-\mathrm{ROM}}$

where $H_{\mathrm{n}-\mathrm{ROM}}$ is calculated using nanometer-sized material properties and local volume fractions of $\mathrm{Cu}, \mathrm{Ta}$ or $\mathrm{Nb}$ $\left(X_{\mathrm{nTa}}, X_{\mathrm{nNb}}\right.$ and $X_{\mathrm{nCu}}$ in Table 3 ) as follows:

$H_{\mathrm{n}-\mathrm{ROM}}=X_{\mathrm{nTa}} H_{\mathrm{nTa}}+X_{\mathrm{nCu}} H_{\mathrm{nCu}}$ or

$H_{\mathrm{n}-\mathrm{ROM}}=X_{\mathrm{nNb}} H_{\mathrm{nNb}}+X_{\mathrm{nCu}} H_{\mathrm{nCu}}$

$H_{\mathrm{nCu}}$ corresponds to the literature data for nanometersized $\mathrm{Cu}$ given earlier. $H_{\mathrm{nTa}}$ was estimated from the Ta and $\mathrm{Nb}$ UTS values $\left(\sigma_{\mathrm{UTS}}(\mathrm{Nb})=1400 \mathrm{MPa}\right.$ and $\sigma_{\mathrm{UTS}}$ $(\mathrm{Ta})=1800 \mathrm{MPa}$ ) by considering (following Tabor's law) that the ratio $H_{\mathrm{nTa}} / H_{\mathrm{nNb}}$ is equal to $\sigma_{\mathrm{y}}(\mathrm{Ta}) / \sigma_{\mathrm{y}}(\mathrm{Nb})$, where $\sigma_{\mathrm{y}}$ are the yield stresses. Since in fully cold worked (nanostructured) bulk materials the UTS value is close to the yield stress, we can consider that $H_{\mathrm{nTa}} / H_{\mathrm{nNb}} \approx \sigma_{\mathrm{UTS}}$ (Ta) $/ \sigma_{\text {UTS }}(\mathrm{Nb})$; with $H_{\mathrm{nNb}}=4.2 \mathrm{GPa}$ (literature data), this gives $H_{\mathrm{nTa}}=5.4 \mathrm{GPa}$. This value must be compared to the literature data for nanostructured bulk Ta. To the authors' knowledge no data are available for such a system. Data can be found for Ta thin films [28,29], where either the substrate affects the nanohardness experiments (at large penetration depth) or a possible indentation size effect can affect the data (at small penetration depth): a hardness of $11 \mathrm{GPa}$ has been reported in these cases. It is also possible to find data for severely deformed Ta, via the equal-channel angular extrusion process, that exhibits a microhardness value of $220 \mathrm{HV}$ [30]. This very low value can be explained by the fact that after a "rather small" true strain of 5, Ta is not already nanostructured but still contains micrometersized grains containing dislocation cells, which cannot be considered as true nanograins. Thus, we consider our estimation $H_{\mathrm{nTa}}=5.4 \mathrm{GPa}$ as a plausible value.

For $\mathrm{Cu} / \mathrm{Ta}$ wires, $\Delta H_{\mathrm{n}-\mathrm{ROM}}$ is plotted versus the conductor diameter $d$ in Fig. 8: its value is always positive and increases as the dimension decreases during the drawing process. This positive deviation from the n-ROM prediction shows that the strength of the $\mathrm{Cu} / \mathrm{Ta}$ nanocomposite zones is greater than a simple combination of individual nanostructured $\mathrm{Cu}$ and $\mathrm{Ta}$ phases. One needs to remember here that these nanostructured phases already exhibit some strengthening due to their microstructural dimensions that induce changes in the plasticity mechanisms such as dislocation starvation (reduced full dislocation nucleation, partial dislocation nucleation, mobility restriction) or grain boundary sliding. Thus the positive value of $\Delta H_{\mathrm{n} \text {-ROM }}$ shows that beside the size effect induced by the nanostructuring of each individual phase there are extra strengthening mechanisms when reducing microstructure size. Among the additional effects is the role of $\mathrm{Cu} / \mathrm{Ta}$ interfaces. In the $\mathrm{Cu} / \mathrm{Nb}$ system, they are observed to be barriers to the motion of dislocations $[13,15]$ : similarly, it can be assumed that the $\mathrm{Cu} / \mathrm{Ta}$ interfaces are sinks to dislocations. Another effect may be the influence of each phase's geometry on the plasticity mechanisms, such as in whiskers considered as one-dimensional systems. To compare this "extra" strengthening in $\mathrm{Cu} / \mathrm{Ta}$ 
and $\mathrm{Cu} / \mathrm{Nb}$ systems, $\Delta H_{\mathrm{n}-\mathrm{ROM}}$ is plotted versus $t_{\mathrm{effT}} \mathrm{Ta}$ and $d_{\mathrm{Nb}}$ (inset in Fig. 8). The $\mathrm{Cu} / \mathrm{Ta}$ samples, at nanometer scales, exhibit lower deviation from n-ROM prediction than $\mathrm{Cu} / \mathrm{Nb}$ samples where $\mathrm{Nb}$ filaments, which are nanowhiskers, are responsible for a strong strengthening effect. This unexpected result is probably due to the distorted two-dimensional ribbon morphology of the Ta filaments that prevents one from considering them as one-dimensional whiskers: the consequence is a lower local strengthening of $\mathrm{Cu} / \mathrm{Ta}$ conductors. The same trend is observed when interpreting the UTS data. The UTS for sample a10 seems to deviate from the ROM value more strongly $(+22.2 \%)$ than that for the $\mathrm{Cu} / \mathrm{Nb}$ conductor $(+11.4 \%)$ with similar theoretical dimensions $\left(d_{\mathrm{Ta}}=810 \mathrm{~nm}\right.$; $\left.d_{\mathrm{Nb}}=830 \mathrm{~nm}\right)$. However, if one takes into account the true size of the Ta ribbons $\left(24 \mathrm{~nm}<t_{\text {eff Ta }}<820 \mathrm{~nm}\right)$ the deviation from ROM appears smaller. The apparent good properties of the $\mathrm{Cu} / \mathrm{Ta}$ system are mainly due to the early refinement of the structure with the curling phenomenon. Moreover, Ta ribbon thickness saturation in very fine wires can also limit the mechanical properties. This size stabilization is probably linked to a deformation restriction caused by the high Ta hardness and by the tangles between $\mathrm{Ta}$ filaments.

Therefore, the positive value $\Delta H_{\mathrm{n}-\mathrm{ROM}}$ shows that the decrease of the dimensions in $\mathrm{Cu} / \mathrm{Ta}$ nanocomposite zones leads to an increase of hardness which is mainly due to the coupling between "traditional" size effects (dislocation starvation) in individual phases and fcc/bcc interface effects. However, extra strengthening resulting from the geometry of the reinforcing filaments (ribbons versus cylindrical fibers) appears weak or nonexistent. Meanwhile the large $\mathrm{Cu}$ channels exhibit rather weak strengthening. As a consequence, these conductors present a complex plasticity distribution: in order to understand the mechanisms of elastic and plastic deformation of the multiscale $\mathrm{Cu}$ matrix and the Ta nanoribbons, neutron scattering experiments with in situ deformation are in progress. This will also help us to measure the stress level at the formation of internal fractures and link these data to the occurrence of internal defects that have prevented, so far, the fabrication of $\mathrm{Cu} / \mathrm{Ta}$ conductors with diameters smaller than $1.3 \mathrm{~mm}$ at $85^{3}$ filament stage. Indeed, the very fine high-strength wires suffer from periodical core fractures, called "central bursting", during hot extrusion and cold drawing at the stages $85^{3}$ and $85^{4}$ filaments [31]. It is worth mentioning that these defects are also observed during the drawing of $\mathrm{Cu} / \mathrm{Ta}$ "in situ" composites [19].

\section{Conclusion}

$\mathrm{Cu} / \mathrm{Ta}$ nanofilamentary wires obtained by SPD applied via successive hot extrusion and cold drawing steps were characterized and compared to $\mathrm{Cu} / \mathrm{Nb}$ conductors. During the fabrication process, a very fine microstructure is achieved in the $\mathrm{Cu} / \mathrm{Ta}$ wires:
- The $\mathrm{Cu}$ microstructure appears similar to that observed in $\mathrm{Cu} / \mathrm{Nb}$ wires: (i) the largest $\mathrm{Cu}$ channels correspond to heavily deformed $\mathrm{Cu}$ composed of grains in the micrometer and nanometer range with a high dislocation density; (ii) the finest $\mathrm{Cu}$ channels are composed of single grains elongated along the drawing axis.

- XRD studies revealed the presence, in $\mathrm{Cu}$, of a major $\left\langle\begin{array}{lll}1 & 1 & 1\end{array}\right\rangle$ texture component with a non-negligible remnant $\left\langle\begin{array}{lll}2 & 0 & 0\end{array}\right\rangle$ component which was not observed in $\mathrm{Cu} / \mathrm{Nb}$ conductors and seems to be associated with recrystallization mechanisms during annealing and hot extrusion steps.

- The Ta filaments develop, like $\mathrm{Nb}$, a strong $\left\langle\begin{array}{llll}1 & 1 & 0\end{array}\right)$ texture.

- TEM studies revealed the development, during drawing steps, of a strong curled structure characterized by the flattening and the interfolding of Ta filaments that become ribbons despite the fact that they were initially cylindrical. This "curling" phenomenon, leading to a very fine microstructure, is not observed in "continuous" $\mathrm{Cu} / \mathrm{Nb}$ conductors: $\mathrm{Nb}$ filaments retain a cylindrical shape and are considered as nanowhiskers.

The difference in microstructural evolution observed in $\mathrm{Cu} / \mathrm{Nb}$ and $\mathrm{Cu} / \mathrm{Ta}$ systems during SPD leads to different mechanical behavior: $\mathrm{Cu} / \mathrm{Ta}$ composites show greater UTS at comparable drawing ratio, which is the result of the intrinsic beneficial mechanical properties of Ta and of an early refinement of the microstructure through the curling phenomenon. Nevertheless, the local study carried out by nanoindentation reveals, in highly drawn $\mathrm{Cu} / \mathrm{Ta}$ wires, a lower deviation from ROM predictions probably also resulting from the Ta microstructure evolution. Indeed, due to their curled flattened morphology, Ta ribbons do not behave as whiskers as observed in $\mathrm{Cu} / \mathrm{Nb}$ nanofilamentary wires, where the whisker effect plays an important role in the high strength obtained.

Furthermore, after high drawing strains, it was shown that the Ta ribbon thickness tends to saturation around $20 \mathrm{~nm}$, which is probably a limitation to further plastic co-deformation of the distorted nanocomposite zones containing the Ta fibers; further reduction of the wire can result in fracture of the ribbons. Thus, it appears difficult to obtain very fine ultrahigh-strength $\mathrm{Cu} / \mathrm{Ta}$ conductors as the strengthening by size reduction through cold drawing is limited: the $\mathrm{Cu} / \mathrm{Ta}$ system becomes too hard to deform and periodical internal fractures occur. $\mathrm{In} \mathrm{Cu} / \mathrm{Nb}$ composites such saturation in the dimension of the fibers was not observed; therefore, a larger drawing ratio is assumed to be attainable for the $\mathrm{Cu} / \mathrm{Nb}$ system without the occurrence of central bursting.

From the electrical point of view, the resistivity of the $\mathrm{Cu} / \mathrm{Ta}$ conductors remains close to $0.4 \mu \Omega \mathrm{cm}$ at $77 \mathrm{~K}$ and therefore satisfies the high-conductivity requirement for magnet applications.

It was shown previously that, during SPD, the reinforcing phase transforms into one-dimensional geometry 
(whiskers) in nanofilamentary $\mathrm{Cu} / \mathrm{Nb}$ wires; to improve the mechanical properties $\mathrm{Ta}$ was chosen to replace $\mathrm{Nb}$ because of the higher shear modulus supposed to enhance the whisker effect. However, the large shear modulus difference between $\mathrm{Ta}$ and $\mathrm{Cu}$ induces higher deformation incompatibility during SPD, leading the reinforcing phase to transform into a less efficient two-dimensional geometry (ribbons). The $\mathrm{Cu} / \mathrm{Ta}$ system is therefore not as efficient as the $\mathrm{Cu} / \mathrm{Nb}$ system for the high-strength requirements for magnet applications.

Finally, the choice of bcc metal to reinforce the $\mathrm{Cu}$ matrix is crucial to attain ultrahigh strength. It appears necessary to consider carefully the combination of material properties at the microscopic scale to obtain a controlled microstructure and an efficient strengthening of nanofilamentary composites. In other words, size and also geometry play key roles in the plasticity of nanomaterials.

\section{Acknowledgements}

The authors thank the technical team of LNCMP, L. Bendichou, G. Coffe, N. Ferreira, J.M. Lagarrigue and J.P. Laurent, who participated in the fabrication of the conductors.

\section{References}

[1] Spencer K, Lecouturier F, Thilly L, Embury JD. Adv Eng Mater 2004;6(5):290.

[2] Bevk J, Harbison JP, Bell JL. J Appl Phys 1978;49(12):6031.

[3] Funkenbusch PD, Courtney TH. Scripta Metall 1989;23:1719.

[4] Spitzig WA, Pelton AR, Laabs FC. Acta Metall 1987;35(10):2427.

[5] Gil Sevillano J. J Phys III 1991;1:967.
[6] Pourrahimi S, Nayeb-Hashemi H, Foner S. Metall Trans A 1992;23A:573

[7] Raabe D, Heringhaus F, Hangen U, Gottstein G. Z Metallkd 1995;86(6):405.

[8] Raabe D, Heringhaus F, Hangen U, Gottstein G. Z Metallkd 1995;86(6):416.

[9] Popova EN, Popov VV, Rodionova LA, Romanov EP, Sudareva SV, Hlebova NE, et al. Scripta Mater 2002;46:193.

[10] Popova EN, Popov VV, Romanov EP, Hlebova NE, Shikov AK. Scripta Mater 2004;51:727.

[11] Hong SI, Hill MA. Scripta Mater 2001;44:2509.

[12] Pantsyrnyi V, Shikov A, Vorobieva A, Khlebova N, Potapenko I, Silaev A, et al. IEEE Trans Appl Supercond 2000;10(1):1263.

[13] Thilly L, Ludwig O, Véron M, Lecouturier F, Peyrade JP, Askénazy S. Philos Mag A 2002;82(5):925.

[14] Dupouy F. Doctoral Thesis, INSA, France; 1995

[15] Thilly L, Lecouturier F, Von Stebut J. Acta Mater 2002;50(20):5049.

[16] Thilly L. Doctoral Thesis, INSA, France; 2000.

[17] Dupouy F, Askénazy S, Peyrade JP, Legat D. Mech Compos Mater 1995;31(4):518

[18] Krotz PD, Spitzig WA, Laabs FC. Mater Sci Eng 1989;A110:37.

[19] Spitzig WA, Krotz PD. Acta Metall 1988;36(7):1709.

[20] Biselli C, Morris DG. Acta Mater 1996;44(2):493.

[21] Sauvage X, Wetscher F, Pareige P. Acta Mater 2005;53:2127.

[22] Thilly L, Colin J, Lecouturier F, Peyrade JP, Grilhé J, Askénazy S. Acta Mater 1999;47(3):853.

[23] Thilly L, Lecouturier F, Véron M, Snoeck E, Peyrade JP, Askénazy S. J Phys IV France 2001;11:33.

[24] Hosford Jr WF. Trans Metall Soc AIME 1964;230:12.

[25] Dupouy F, Snoeck E, Casanove MJ, Roucau C, Peyrade JP, Askénazy S. Scripta Mater 1996;34(7):1067.

[26] Kraft FF, Chakkingal U, Baker G, Wright RN. J Mater Process Technol 1996;60:171.

[27] Oliver WC, Pharr GM. J Mater Res 1992;7:6.

[28] Saha R, Barnard JA. J Cryst Growth 1997;174:495.

[29] Nguyen TD, Barbee Jr TW. Mater Res Soc Symp Proc 1998;522:269.

[30] Sandim HRZ, McQueen HJ, Blum W. Scripta Mater 2000;42:151.

[31] Vidal V, Thilly L, Lecouturier F. Mater Sci Forum 2006;503-504:639. 